\title{
ADVANCED SUPERALLOYS AND TAILORED MICROSTRUCTURES FOR INTEGRALLY CAST TURBINE WHEELS
}

\author{
R. C. Helmink*, R. A. Testin*, A. R. Price**, R. Pachman**, G. L. Erickson ${ }^{\dagger}$, K. Harris ${ }^{\dagger}$, J. A. Nesbi $\iota^{\dagger \dagger}$, and J. F. Radavich ${ }^{\ddagger}$ \\ * Rolls-Royce Corporation, Indianapolis, Indiana; ** Howmet Research Corporation, Whitehall, Michigan; \\ ${ }^{\dagger}$ Cannon-Muskegon Corporation, Muskegon, Michigan; ${ }^{\dagger \dagger}$ NASA Glenn, Cleveland, Ohio; \\ ${ }^{\ddagger}$ Micro-Met Laboratories, West Lafayette, Indiana
}

\begin{abstract}
Introduction
The life cycle costs of the Rolls-Royce Corporation Model 250 small turbine engines have not kept pace with those of international competitors. A significant contributor to this deficiency was the dated technology used in turbine section materials and manufacturing processes. The Advanced Materials for Small Turbine Engines (AMSTE) team, consisting of RollsRoyce Corporation, Howmet Corporation, Cannon-Muskegon Corporation, Purdue Research Foundation, and the National Aeronautics and Space Administration (NASA) Glenn Research Center, was formed to significantly advance the state of the art in the manufacture of integrally bladed turbine wheels. The team was awarded a program by NASA for the Aerospace Industry Technology Program (AITP) designed to help maintain competitiveness in the production of small turboshaft engines and demonstrate an advanced material system for other gas turbine aerospace/surface applications.
\end{abstract}

The goals for this program were to develop the technology base needed to protect the small turbine engine industry by doubling or tripling the life of current gas generator turbine wheels and significantly reducing their life cycle cost. Specifically, this program addressed the development of advanced superalloy materials and manufacturing processes to make possible an affordable turbine wheel with significantly increased low cycle fatigue (LCF) life and improved airfoil stress rupture life.

To meet these goals, a technical effort was formulated to develop an integrally bladed turbine wheel casting technology that would provide equivalent or superior capabilities at a substantially lower cost when compared to conventional mechanically attached bladed designs. The technical plan included a moderate risk "baseline" approach, featuring a state-of-the-art Grainex ${ }^{(\mathrm{GX})}$ casting process using Mar-M247 superalloy and an improved wheel design, and two higher risk approaches involving development/ evaluation of advanced superalloys and tailored cast microstructures. The two highcr risk efforts are the subject of this paper.

\section{Advanced Alloy Evaluations}

The advanced alloy studies investigated the relative potential of derivative directionally solidified (DS) and single crystal compositions when utilized for investment cast integrally bladed turbine wheel designs. The alloys studied were compositional variants of the second-generation 3\% rhenium (Re) containing DS alloy $\mathrm{CM} 186 \mathrm{LC}^{\otimes 1}$ and the third-generation $6 \% \mathrm{Re}$ containing single crystal alloy CMSX ${ }^{\circledast}-10^{2}$. The nominal compositions of the alloys investigated within this program are provided in Table I. Previous attempts to make equiaxed castings using the CM 186 LC alloy with no modification in composition or heat treatment were unsuccessful because the creep rupture properties were inadequate ${ }^{3}$. The compositional modifications made in support of the present program focused on increasing grain boundary strength and ductility while maintaining microstructural stability.

The master alloys were used to produce Rolls-Royce Corporation Model 250 first-stage turbine wheels using Howmet's GX casting process to refine the grain structure in the web and hub of the wheels. The GX process utilizes oscillatory mold rotation to control convective fluid flow, the rate of heat transfer out of the casting and the resultant grain structure. ${ }^{4-6}$ All GX wheel casting was performed at the Howmet LaPorte Casting Facility. The 
Table I. Nominal compositions of first, second, and third generation superalloys (weight \%).

\begin{tabular}{lllllllllllllll} 
Alloy & Cr & Co & Mo & W & Re & Nb & Ta & Al & Ti & Hf & C & B & Zr & Ni \\
\hline Mar-M246 & 9 & 10 & 2.5 & 10 & & & 1.5 & 5.5 & 1.5 & & 0.15 & 0.015 & 0.05 \\
Mar-M247 & 8.4 & 10 & 0.65 & 10 & & & 3.1 & 5.5 & 1 & 1.4 & 0.16 & 0.015 & 0.05 \\
CM 186 LC & 6 & 9 & 0.5 & 8 & 3 & & 3 & 5.7 & 0.7 & 1.4 & 0.07 & 0.015 & $0.005 \mathrm{Bal}$ \\
CM 186 Mod & 5.9 & 9.4 & 0.4 & 8.5 & 3 & & 3.3 & 5.7 & 0.75 & 1.5 & 0.09 & 0.019 & 0.01 & $\mathrm{Bal}$ \\
CM 681 & 5.4 & 9.3 & 0.5 & 8.5 & 3 & & 6.2 & 5.7 & 0.15 & 1.6 & 0.11 & 0.018 & $0.015 \mathrm{Bal}$ \\
CM 681A & 5 & 9.3 & 0.5 & 9 & 3 & & 6.9 & 5.7 & & 1.6 & 0.11 & 0.018 & $0.025 \mathrm{Bal}$ \\
\hline CMSX-10 & 2 & 3 & 0.4 & 5 & 6 & 0.05 & 8 & 5.7 & 0.2 & 0.03 & & & Bal \\
CM 4670 & 4 & 3.4 & 0.5 & 5 & 5.3 & 0.05 & 8 & 5.7 & 0.13 & 1.2 & 0.09 & 0.017 & $0.015 \mathrm{Bal}$ \\
CM 4670C & 2.7 & 3.2 & 0.4 & 5 & 6 & 0.05 & 8 & 5.7 & 0.08 & 1.2 & 0.05 & 0.02 & $0.025 \mathrm{Bal}$ \\
CM 4670D & 1.7 & 3 & 0.35 & 5 & 5.7 & 0.05 & 8 & 5.7 & & 1.7 & 0.1 & 0.018 & $0.015 \mathrm{Bal}$ \\
CM 4670E & 1.7 & 3 & 0.4 & 5 & 5 & 0.05 & 8.3 & 5.8 & & 1.7 & 0.12 & 0.018 & $0.015 \mathrm{Bal}$
\end{tabular}

wheels were evaluated for compatibility with the GX casting and postcasting processing, microstructural stability during thermal processing and expected service conditions, and critical mechanical and environmental properties.

\section{Iteration 1-Wheel Casting}

The first casting iteration evaluated the CM 186 MOD, CM 681, CM 4670 and CM $4670 \mathrm{C}$ alloys. Macrostructure examination of integral and cross-sectioned wheels revealed uniform equiaxed grains in the rim, bore, and stub areas (Figure 1). The grain structure and porosity levels in these wheels were similar to production Mar-M247 cast wheels produced using the GX casting method. Since the porosity in the GX cast wheels was not surface connected, a full densification would be expected during subsequent hot isostatic pressing (HIP) processing.

Fluorescent penetrant inspection (FPI) revealed severe airfoil cracking in the CM 4670 and CM $4670 \mathrm{C}$ wheels. The cracks were classified as hot tear cracks and were intergranular. No airfoil cracking was observed in the CM 186 MOD and CM 681 wheels.

Microstructural examination of the as-cast wheels showed comparable grain sizes in the hub and rim areas for all four compositions. However, the airfoil grain size was somewhat finer in the CM 681 and CM $4670 \mathrm{C}$ wheels. A higher volume fraction of gamma/gamma prime eutectic phase was observed in the CMSX-10 variant wheels. This is credited to higher gamma prime forming element and refractory element content in the alloys.

\section{HIP and Heat Treat Studies}

One GX cast wheel from each of the four modified CM $186 \mathrm{LC}$ and CMSX-10 compositions was processed at $1185^{\circ} \mathrm{C} / 172 \mathrm{MPa} / 4$ hr. This cycle is the standard production cycle used for GX cast Mar-M247 components. Metallographic examinations of the

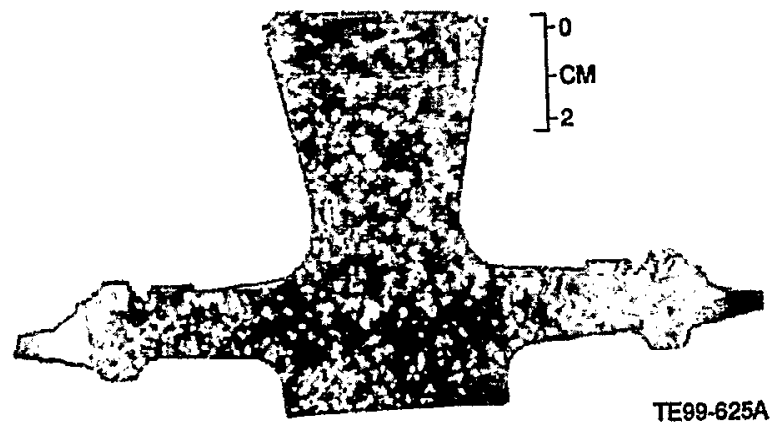

Figure 1. Macrostructure of Rolls-Royce Corporation Model 250 CM $681 \mathrm{GX}$ wheel. advanced alloy wheels revealed the presence of some residual porosity. It was suspected that adding rhenium increased the high temperature strength of the alloy and prevented full densification; therefore, an additional four wheels were HIP processed at a higher temperature and pressure $\left(1232^{\circ} \mathrm{C} / 200\right.$ $\mathrm{MPa} / 4 \mathrm{hr}$ ). Metallographic examinations of this material revealed complete pore closure. The higher HIP temperature and pressure did not result in noticeable grain growth or in indications of incipient melting.

Optical microscopy and scanning electron microscopy (SEM) were performed on various sections of the wheels (airfoil, outer web, and inner web) in the as-cast and as-HIPed conditions and with post HIP resolutioning thermal treatments of 1232,1246 , 1260 , and $1274^{\circ} \mathrm{C}$ for 2 to 5 hours. As-cast structures exhibited relatively uniform blocky gamma prime and no evidence of topologically close-packed (TCP) phases (Figure 2a). However, significant gamma prime coarsening and carbide degeneration occurred as a result of the high HIP temperature utilized to close the residual casting porosity and the subsequent high solution heat treat temperatures employed. In addition, the CMSX-10 variants exhibited some microstructural instabilities in the form of TCP needle phases from the postcasting thermal processing (Figure 2b). In an effort to restore the desired gamma prime morphology, high temperature solutioning treatments of $1271^{\circ} \mathrm{C} / 3 \mathrm{hr}$ for the $\mathrm{CM} 186$ variants and $1288^{\circ} \mathrm{C} / 5 \mathrm{hr}$ for the CMSX-10 variants were selected followed by gas fan cooling (GFC) and double aging at $1093^{\circ} \mathrm{C} / 2 \mathrm{hr} / \mathrm{GFC}+871^{\circ} \mathrm{C} / 20 \mathrm{hr} / \mathrm{GFC}$.

\section{Microstructural Characterization}

SEM and energy dispersive spectroscopy (EDS) were cmployed to document the changes in carbide morphology occurring during the high temperature thermal treatments. The as-cast material showed many script MC carbides (Figure 3a). There are also a number of discrete carbides present near the primary gamma prime islands. Both the script and discrete carbides showed very high Ta content. The discrete carbides also showed some Hf.

The high temperature thermal treatments progressively break down the script $\mathrm{TaC}$ phase to release carbon to form $\mathrm{HfC}$ precipitates where Hf segregation exists, generally near primary gamma prime areas (Figure 3b). The carbon tied up as $\mathrm{HfC}$ cannot form the secondary $\mathrm{Cr}$ carbides at the grain boundaries and $\mathrm{Cr}$ concentrations can then lead to sigma formation. Since $\mathrm{Hf}$ is added to $\mathrm{Ni}$ base alloys to improve ductility at $760^{\circ} \mathrm{C}^{7}$, loss of beneficial Hf in the gamma prime is detrimental. The Re appears not to take a significant part in primary carbide formation and is contained primarily in the gamma phase.

\section{Specimen Testing}

The mechanical testing of HIP processed and fully heat treated GX cast wheels included room temperature and $538^{\circ} \mathrm{C}$ tensile tests, stress rupture tests, LCF tests at $538^{\circ} \mathrm{C}$, and fatigue crack growth (FCG) testing at $538^{\circ} \mathrm{C}$. These tests all were performed using material removed from the disk portion of the wheel. In addition, airfoil miniflat stress rupture tests were conducted.

The $0.2 \%$ yield strengths and ultimate tensile strengths of all four advanced alloys were equal or somewhat higher than the baseline GX Mar-M247 material.

Stress rupture results for the hub portion of the wheels are shown in Figure 4. The CM 186 variants were superior to the Mar-M247 baseline alloy at low stresses, but inferior at high stresses. The CMSX-10 variants were equivalent to Mar-M247 at low stresses and significantly worse at high stresses. 


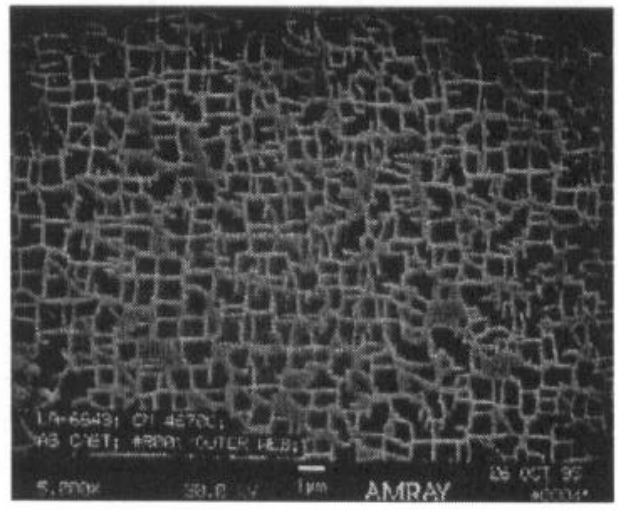

As-cast

a)

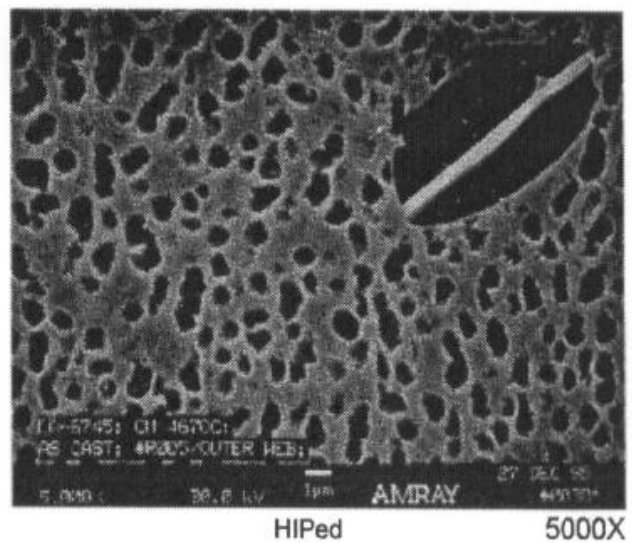

b)

TE00-47

Figure 2. As-cast and as-HIPed microstructures from outer web area of CM 4670C GX wheel.

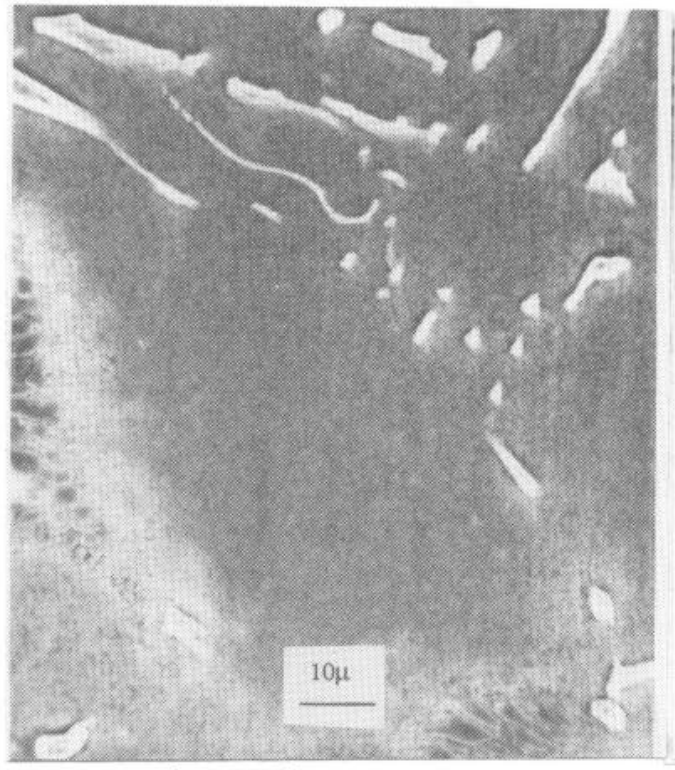

As-cast

a)

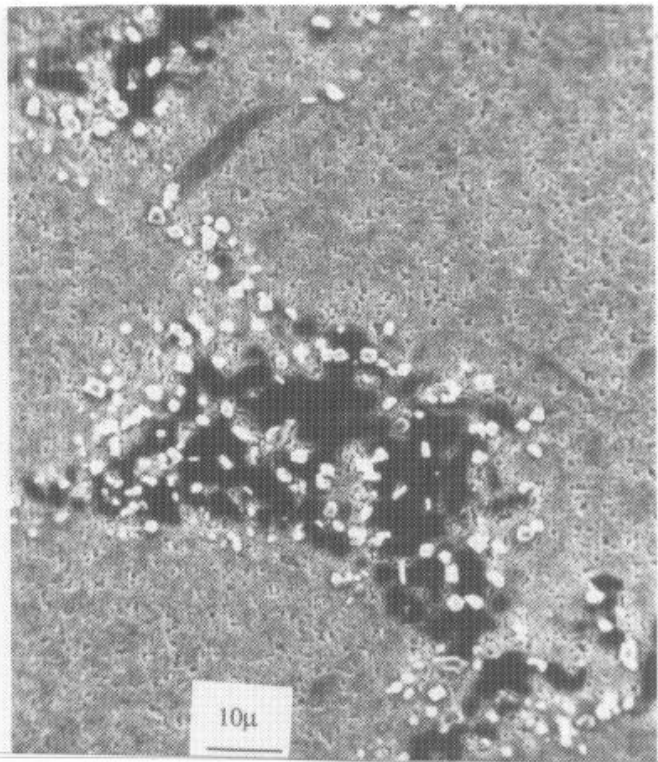

Simulated HIP + solution + age

b)

Figure 3. Carbide morphology of CM 681 test bars versus heat treat condition.

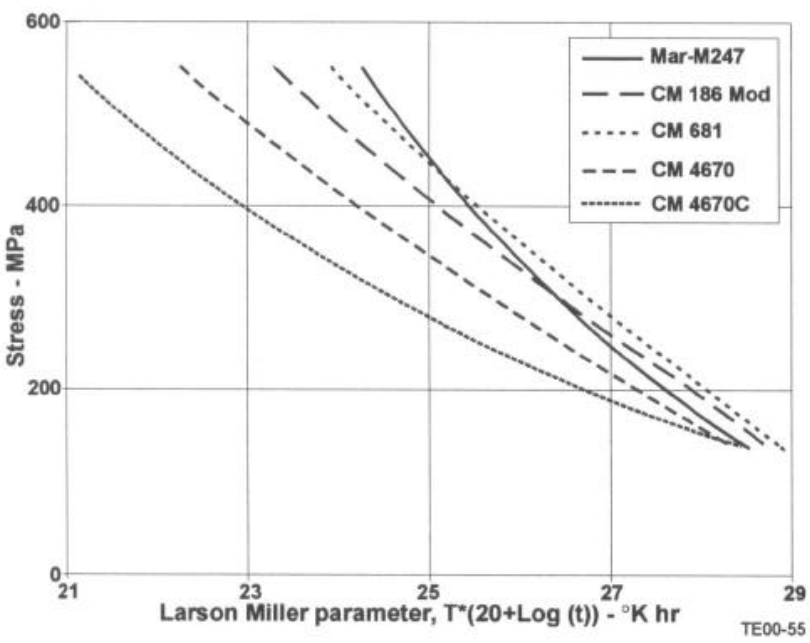

Figure 4. Hub stress rupture results from first-iteration equiaxed alloy variants.
The airfoil miniflat stress rupture lives of all four advanced alloys were roughly equivalent to each other and to the baseline Mar-M247 at the lowest stress level tested. At higher stresses, more divergence in rupture life was observed among the advanced alloys and all of the alloys were inferior to the baseline material.

The LCF capability of the CM 186 variants showed a crossover with Mar-M247 with the baseline alloy having an advantage at lower strain ranges. Since the critical portion of the wheel operates at high strain ranges, these curve shapes are favorable for the advanced alloys. The CMSX-10 variants showed reduced lives at all strain ranges.

The FCG test results are summarized in Figure 5. Surprisingly, all of the advanced alloys showed some advantage in FCG resistance over the critical stress intensity range of 20 to $40 \mathrm{MPa} \vee \mathrm{m}$.

Burner rig sulfidation testing was performed by NASA Glenn. The test conditions were $899^{\circ} \mathrm{C}$ and Mach 0.3 air flow using JP5 fuel with 2 ppm by weight of synthetic sea salt. Each cycle consisted of 


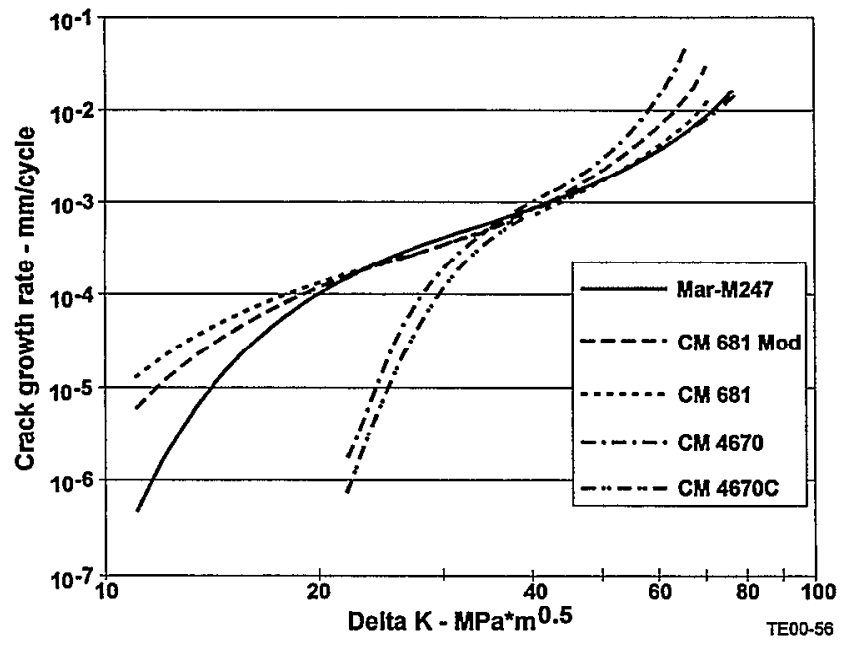

Figure 5. FCG summary from first-iteration of equiaxed alloy variants.

$1 \mathrm{hr}$ at temperature in a rotating carousel followed by a cold air blast. The weight change data are shown in Figure 6 . All four advanced alloys performed considerably better than the baseline Mar-M247 alloy. Although the advanced alloys show improved corrosion resistance, a coating would be required because Model 250 engines often operate in corrosive environments.

\section{Iteration 1 Conclusions}

At the conclusion of the first iteration of advanced alloy evaluations, it was postulated the mechanical properties of the advanced alloys were being adversely affected by the thermal processing routes selected for the materials. Specifically, it was suggested the relatively slow cooling rates achieved during HIP processing caused excessive gamma prime coarsening. Subsequent heat treatment after HIP processing using a higher solution temperature and gas fan cooling did not restore the desired gamma prime sizes and morphology.

In addition, all of the high temperature processing was expected to have an adverse effect on carbide composition and morphology.

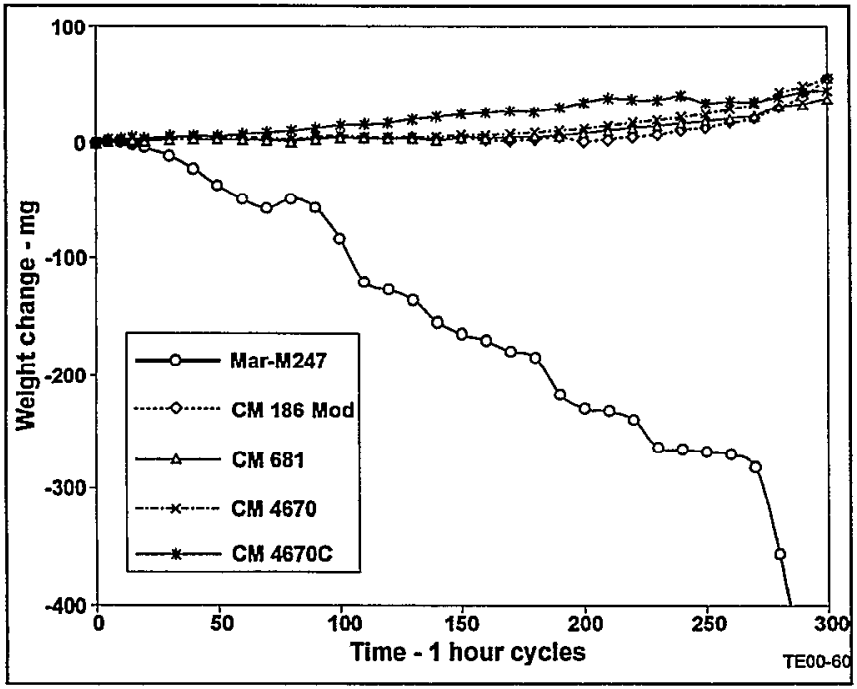

Figure 6. Bumer rig hot corrosion test results from the Mar-M247 and modified CM $1862 \mathrm{c}$ and CMSX-10 alloys.
Fractographic analysis on selected airfoil miniflat stress rupture bars revealed much smoother grain boundary fracture surfaces for the advanced alloys than the Mar-M247 baseline material. This suggests the grain boundary carbide morphology was less well developed during heat treatment for the advanced alloys than the Mar-M247 baseline material.

Also, it was clear the phasal stability of the modified CMSX-10 alloys was limited and they could not withstand the high temperature post casting thermal processing.

\section{Advanced Alloy Test Bar Evaluations}

To separate the effects of composition and thermal processing on mechanical properties, test bar castings were produced from each of the seven advanced alloy compositions and evaluated with various thermal processing conditions prior to initiating the second iteration of advanced alloy wheel casting.

The results of this testing can be summarized as:

- The phasal stability of the CMSX-10 variants was inadequate to withstand the high temperature postcasting thermal processing required for integrally cast $\mathrm{GX}$ wheels.

- The modified CMSX-10 alloys would be dropped from the program.

- CM 186 MOD alloy was noticeably weaker than the other two advanced alloys and also would be dropped from the program.

- The HIP conditions required to achieve pore closure and HIP cooling rate were key variables.

Iteration 2-Wheel Casting

Rolls-Royce Corporation Model 250 first-stage wheels were produced using CM 681 and CM 681A alloys and the Howmet GX casting process. The surface grain structures were uniform for wheels from both alloys. Grain sizes in the hub and rim appeared to be comparable to current production GX Mar-M247 cast wheels for both advanced alloy compositions.

\section{HIP and Heat Treat Optimization}

A series of wheels were HIPed at $200 \mathrm{MPa}$ for $4 \mathrm{hr}$ at temperatures ranging from 1185 to $1218^{\circ} \mathrm{C}$. The initial metallographic examination of HIPed wheels for pore closure used specimens taken from the central hub region. The central hub is the thickest part of the casting and the last area to solidify; therefore, it was believed to be the area most prone to microshrinkage and the last area that HIP would close. Specimens removed from the central hub area of these wheels showed no evidence of residual microporosity. Subsequently, it was also decided to examine specimens from the web and rim areas for residual porosity, because small microshrinkage was occasionally observed on the fracture surfaces of the failed stress rupture bars. Surprisingly, scveral small pores with incomplete closure were located in the center of the rim area. Presumably, the greater susceptibility to microporosity in the rim area is related to the forced fluid flow during solidification associated with $\mathrm{GX}$ processing. The maximum pore size observed was 3 millimeters $(\mathrm{mm})$ and was generally less than $1 \mathrm{~mm}$. These results were reviewed with the materials applications engineers for the Model 250 engine and failure analysts at Rolls-Royce Corporation familiar with this engine. It was determined this small amount of residual porosity would be inconsequential to engine performance.

It was concluded from the HIP assessment studies that minimizing the HIP temperature was beneficial to mechanical properties with 
the advanced alloys. Accordingly, one GX wheel each of alloy CM 681 and $\mathrm{CM} 681 \mathrm{~A}$ were HIPed at $1204^{\circ} \mathrm{C} / 200 \mathrm{MPa} / 4 \mathrm{hr}$ and a second $\mathrm{CM} 681$ alloy wheel was HIPed at $1185^{\circ} \mathrm{C} / 200 \mathrm{MPa} / 4 \mathrm{hr}$. One group of specimens from each wheel received the standard age of $1093^{\circ} \mathrm{C} / 2 \mathrm{hr} / \mathrm{GFC}+871^{\circ} \mathrm{C} / 20 \mathrm{hr} / \mathrm{GFC}$. A second group received a modified age of $1038^{\circ} \mathrm{C} / 2 \mathrm{hr} / \mathrm{GFC}+871^{\circ} \mathrm{C} / 20 \mathrm{hr} / \mathrm{GFC}$. A third group received a $1204^{\circ} \mathrm{C} / 2 \mathrm{hr} / \mathrm{GFC}$ partial resolution followed by the modified double age.

The stress rupture lives at $843^{\circ} \mathrm{C} / 552 \mathrm{MPa}$ were 200 to $300 \%$ of baseline Mar-M247 lives for both advanced alloys and all three thermal processing conditions. The results from stress rupture tests conducted at $1038^{\circ} \mathrm{C} / 138 \mathrm{MPa}$ are presented in Figure 7 . The lower temperature processing appeared to provide a significant improvement in the rupture life. The CM 681 alloy exhibited a somewhat higher rupture life than the CM 681A alloy. The LCF testing results are also shown in Figure 7. Most of the advanced alloy and thermal processing combinations provided improved LCF lives compared to the baseline Mar-M247 material examined. It also appears the resolutioning after HIP offers a benefit to fatigue life.

Overall, the $1185^{\circ} \mathrm{C}$ HIP followed by the modified age appeared to offer the best balance of properties, and this thermal processing was selected for the balance of the CM 681 and CM 681A wheels.

\section{Specimen Testing}

The test plan was identical to that employed for the first-iteration wheel evaluations. The testing included room temperature and $538^{\circ} \mathrm{C}$ tensile tests, stress rupture tests, LCF tests at $538^{\circ} \mathrm{C}$, and crack growth testing at $538^{\circ} \mathrm{C}$. The tests were all performed using material removed from the disk portion of the wheel. In addition, airfoil miniflat stress rupture tests were conducted.

The $0.2 \%$ yield strength and ultimate tensile strength of the CM 681 alloy was somewhat lower than the values achieved for this alloy in the first iteration and closer to the strength levels of Mar-M247. This represents the desired result, since a higher strength could disrupt the required burst sequence between the first-stage and second-stage turbine wheels and thereby force a redesign. No significant difference was observed in strength or ductility between CM 681 and CM 681A.

Stress rupture results for the hub portion of the wheels are shown in Figure 8. Both advanced alloys performed significantly better than the baseline Mar-M247 alloy at all stress levels. Compared to

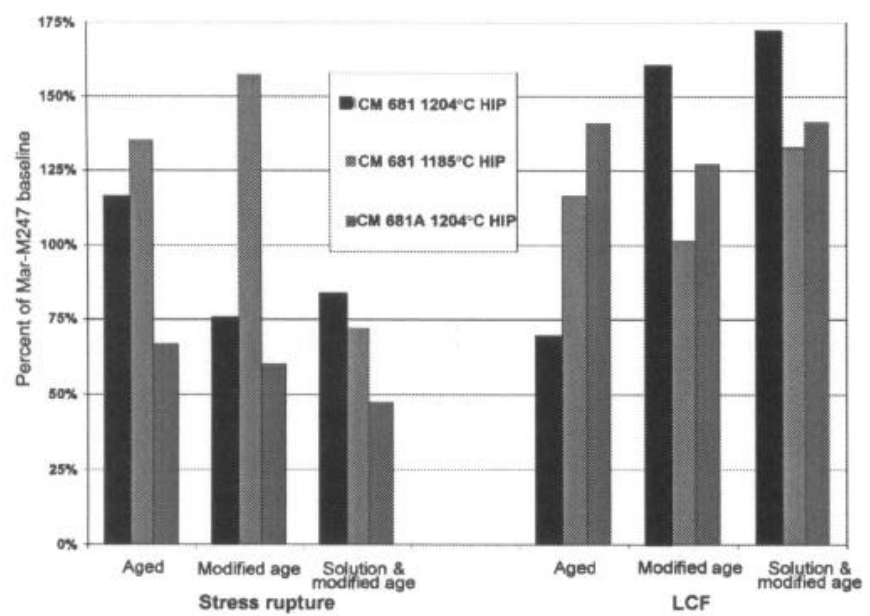

Figure 7. Results for iteration $2843^{\circ} \mathrm{C} / 552 \mathrm{MPa}$ stress rupture and $538^{\circ} \mathrm{C} / \mathrm{R}=0 / \mathrm{Kt}=1 / \Delta \varepsilon=0.95 \%$ LCF HIP and heat treat optimization study.

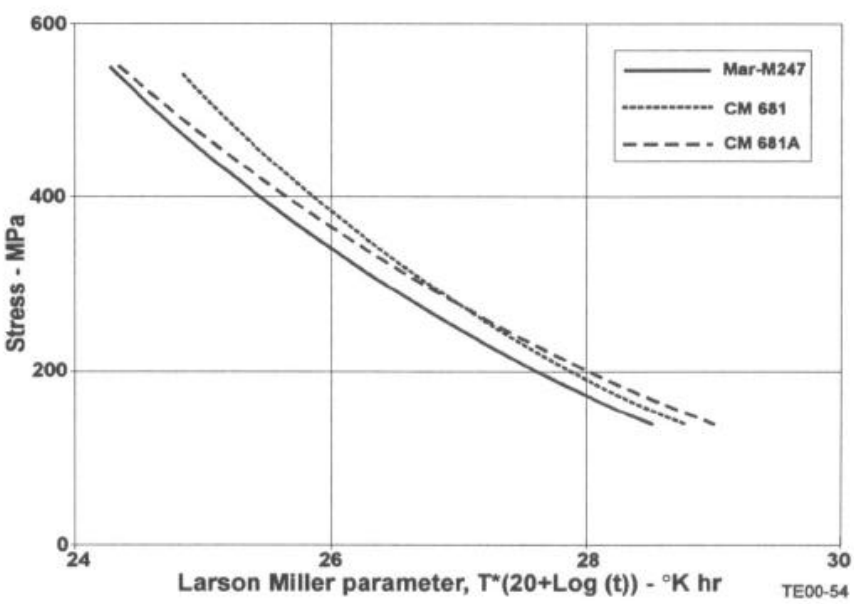

Figure 8. Hub stress rupture results from second-iteration equiaxed alloy variants.

the results of the CM 186 derivative alloys in the first iteration, it is evident the second-iteration thermal processing provides better performance in the high stress portion of the curve while maintaining an advantage over Mar-M247 in the low stress region. CM 681 performed slightly better than CM 681A at low stresses and $\mathrm{CM}$ 681A was superior at high stresses.

The airfoil miniflat stress rupture test results are provided in Figure 9 . The advanced alloys are clearly superior to the baseline Mar-M247 alloy throughout the stress range investigated. This is in stark contrast to the first-iteration results in which the advanced alloys were dramatically inferior to the baseline material at high stresses. The CM 681A alloy exhibited a small advantage over the CM 681 alloy at higher stresses and a more distinct advantage in the low stress region.

The LCF test results are shown in Figure 10. The two CM 186 derivative alloys performed similarly. Both alloys were superior to Mar-M247 in the low life, high strain range portion of the curve and inferior to the baseline in the high life, low strain range region. Since the critical portion of the wheel operates at high strain ranges, these curve shapes are favorable for the advanced alloys. This is the same trend observed in the first- iteration results for the CM 186 derivative alloys, indicating the alternative thermal processing had only a minor effect on LCF properties.

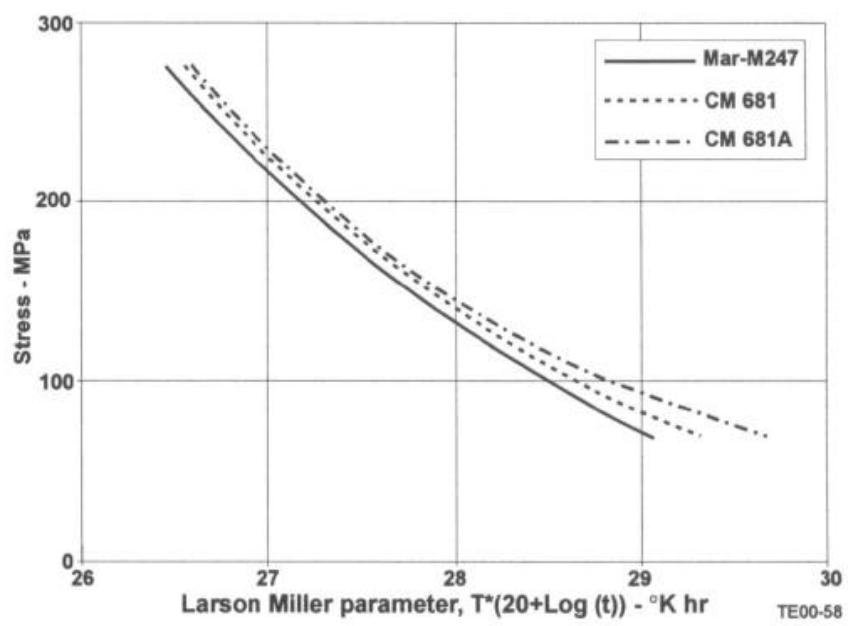

Figure 9. Airfoil miniflat stress rupture results from seconditeration equiaxed alloy variants. 


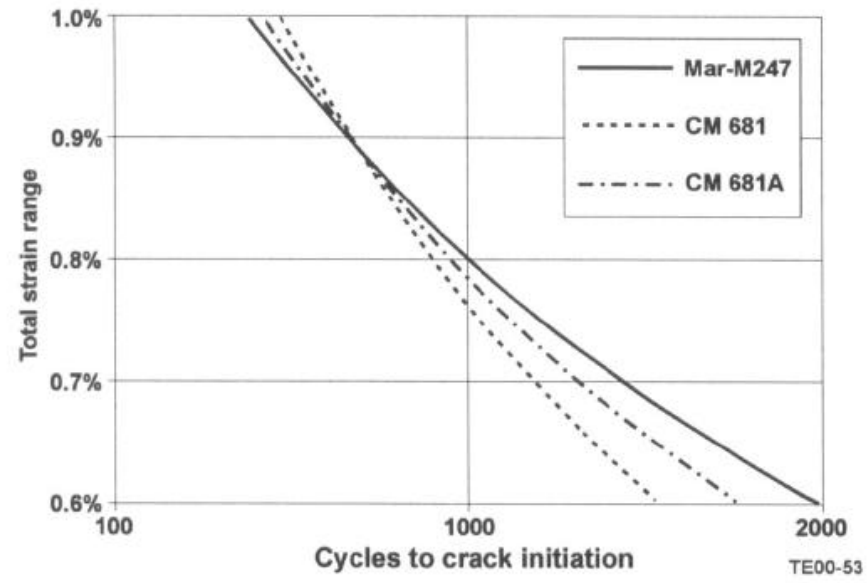

Figure 10. Hub LCF results from second-iteration equiaxed alloy variants.

The FCG test results are provided in Figure 11. The CM 681A alloy was similar to the baseline Mar-M247 material. The CM 681 alloy appears to offer a significant advantage in crack growth resistance compared to the baseline. Crack growth tests tend to be variable and the extent of testing conducted on this program was limited. Nevertheless, the CM 681 results were encouraging and would provide a major benefit to wheel life if this advantage is realized in engine testing.

In summary, both $\mathrm{CM} 681$ and $\mathrm{CM}$ 681A exhibit significant advantages over the baseline Mar-M247 material. CM 681 was selected for the manufacturing scale-up because of its potential for greatly increased crack growth resistance.

\section{Process Modeling and Validation of Tailored Cast Structures}

The objective of the tailored cast microstructure effort was to produce DS airfoils in an integral turbine wheel that would then transition into a fine grain GX web and hub. Previous attempts by Howmet and others to produce integral wheels with DS airfoils were successful on occasion; however, process repeatability was lacking due to inadequate understanding and control of the key variables affecting the modified GX process. ${ }^{9-11}$ Other technical difficulties included poor grain control in the airfoils, poor control of the coarse-to-fine grain structure transition, significant mold structural problems, and significant labor in put for each cast

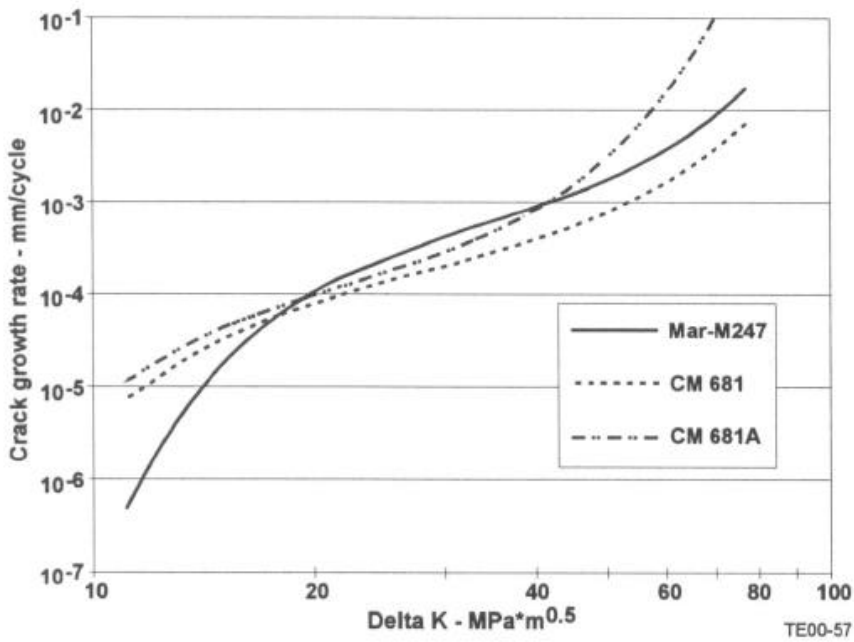

Figure 11. FCG summary from second-iteration equiaxed alloy variants. wheel. In the present investigation Howmet relied heavily on their expertise with process modeling and manufacturing simulation tools to minimize trial and error experimentation.

The initial simulations and casting trials focused on improving the directionality of the airfoil grains. The goal of the simulations was to minimize axial and circumferential thermal gradients and isotherm velocities through the combined use of a radial heat sink, tailored pattern features, mold composition and thickness, wrapping procedures, and foundry parameters.

This iterative approach of model predictions followed by casting trials resulted in progressive improvement of the oriented grain structure with the later trials showing excellent orientation and directional solidification. The resultant process was designated DS/GX ${ }^{\circledast}$. The initial casting trials also exhibited some mold splitting, but this problem was essentially eliminated with additional casting modifications. One defect that remained a concern was hot tears in the airfoil area. Figure 12 shows an example of the hot tears that occur in both the radial and tangential directions.

To address the airfoil hot tearing, stress modeling was used in conjunction with the fluid-thermal modeling to optimize the starter geometry. A number of thermal stress models were evaluated to simulate the relative hoop and tensile stress levels of the baseline and alternative geometries. Following the stress evaluation, fluid-thermal models were solved to assess the effects the modifications would have on the directional solidification of the airfoils. Tool modifications were made based upon the design showing the best improvement in both stress level and temperature gradient orientation. Figure 13 shows the three component temperature gradients for the revised configuration. The gradients were better aligned orthogonal to the airfoil stacking axis for the revised configuration than the baseline and resulted in better airfoil grain orientation as well as a significant reduction in overall stress levels.

Additional wheels were cast and overall the exceptional grain orientation quality was retained (Figure 14); however, airfoil hot tearing, while significantly reduced, was not eliminated. Since

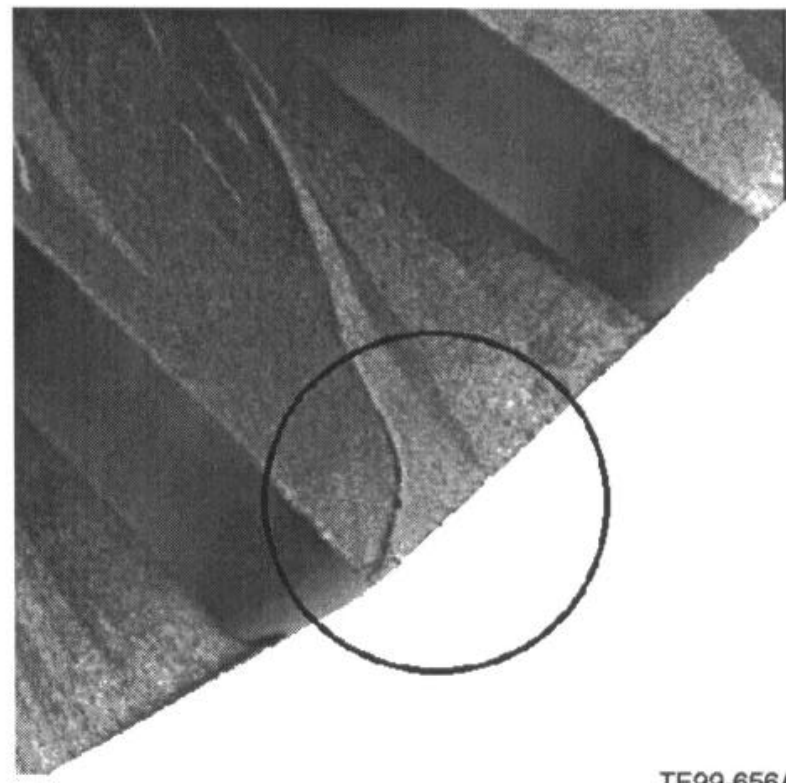

TE99-656A

Figure 12. Typical hot cracking in the airfoils of the DS/GX cast wheel. 


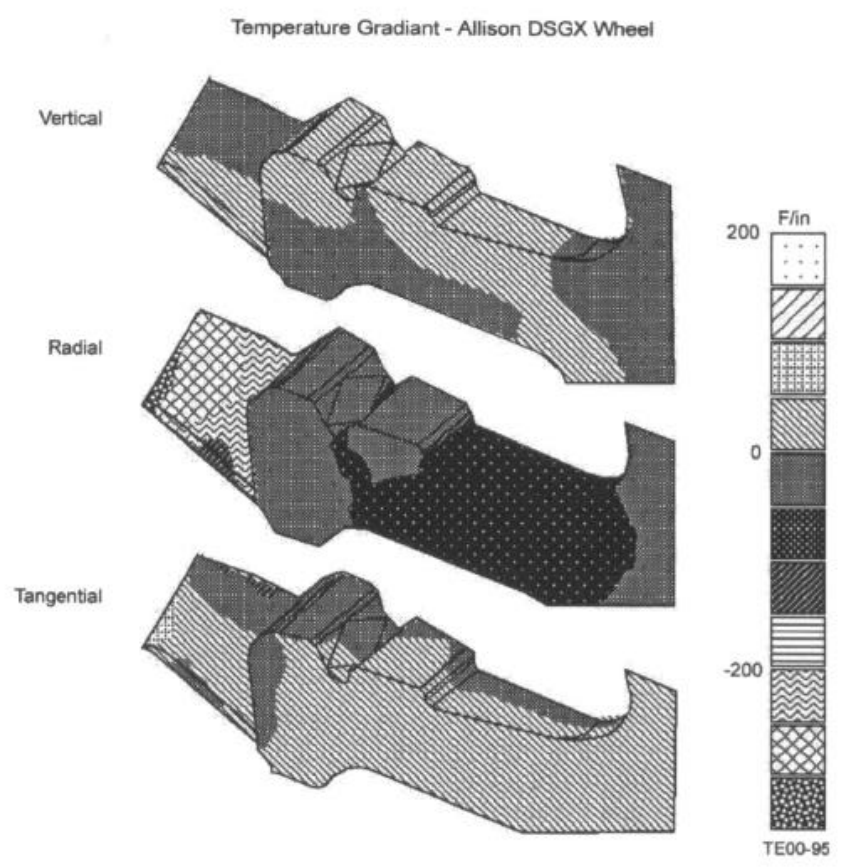

Figure 13. Temperature gradients for the revised configuration for the modified DS/GX cast wheel.

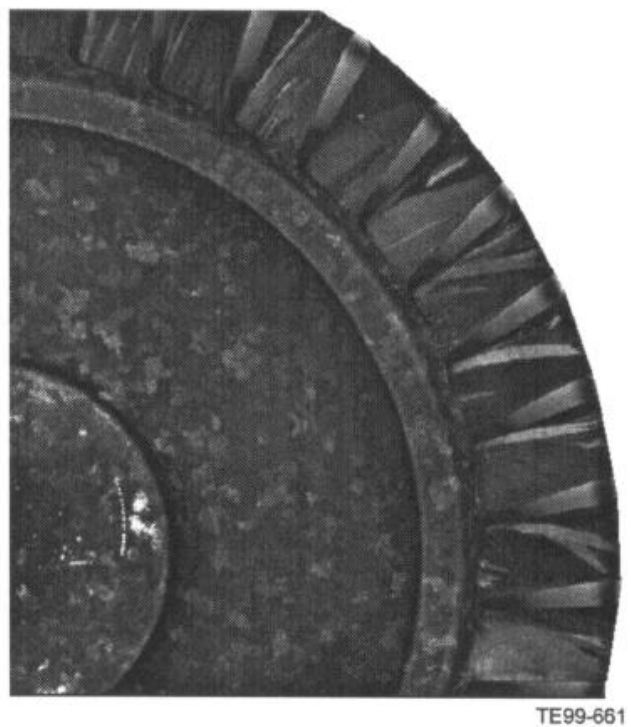

Figure 14. DS/GX cast Mar-M247 wheel from the final casting trial showing directionally oriented grain in airfoils.

the airfoil hot tearing issue remained, a compromise process that eliminated the radial heat sink and utilized special mold configurations and casting processes to produce large, partially aligned grains in the airfoil was developed. This modified GX casting process has been termed Pseudo DS/GX casting. This process was demonstrated on a wheel shown in Figure 15.

\section{DS/GX and Pseudo DS/GX Specimen Testing}

Tensile and stress rupture testing was conducted on specimens taken from the columnar-to-equiaxed transition zone in several wheels. The tensile specimens all failed in the columnar grain region and exhibited base material strength and ductility. The transition area stress rupture specimens all failed in the equiaxed

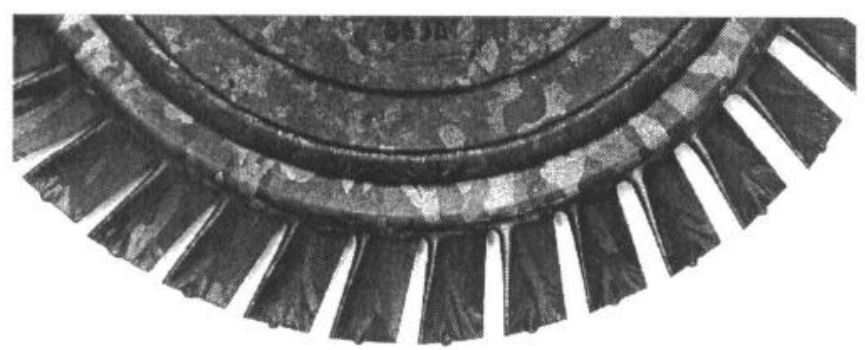

TE99-654

Figure 15. Pseudo DS/GX cast Mar-M247 wheel from casting trial 3 showing enlarged grain in airfoils.

region with equivalent life versus the base material. Metallographic examination of transition areas revealed no unusual phases or microstructural features.

Testing also included tensile, stress rupture, and LCF tests using material removed from the disk portion of the wheel as well as airfoil miniflat stress rupture tests. The higher temperature foundry parameters associated with DS/GX and Pseudo DS/GX processing produced little or no reduction in yield and tensile strength and may have benefited ductility to a small extent.

The Pseudo DS/GX processing provided significant benefits to airfoil stress rupture life for both alloys and DS/GX processing adds another significant improvement in life as shown in Figure 16. The DS/GX and Pseudo DS/GX processing had little or no effect on hub stress rupture or LCF with Mar-M247, but caused some degradation in rupture life at high stresses and a substantially lower LCF life in the high strain range portion of the curve with CM 681. The LCF results are shown in Figure 17.

Apparently the higher processing temperatures caused enough microstructural damage in the CM681 alloy to partially offset the benefits obtained from the modified HIP, solution, and aging thermal treatments developed during this program.

\section{Manufacturing Scale-Up}

\section{Wheel Casting}

The AMSTE team selected CM 681 as the advanced alloy and Pseudo DS/GX for the advanced casting process, but concluded there were not yet sufficient data to make a final selection regarding the best combination of alloy and casting process.

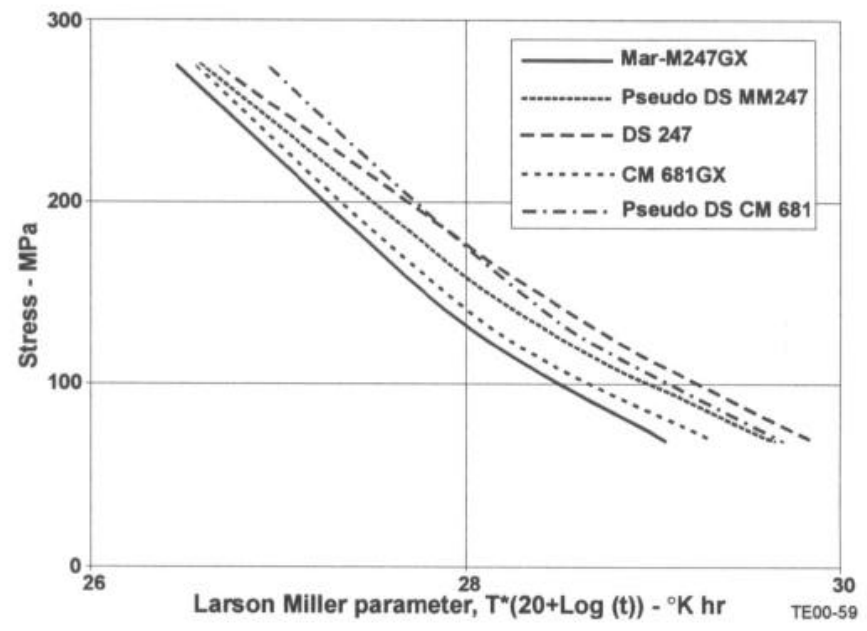

Figure 16. Airfoil miniflat stress rupture results from DS/GX and Pseudo DS/GX wheels. 


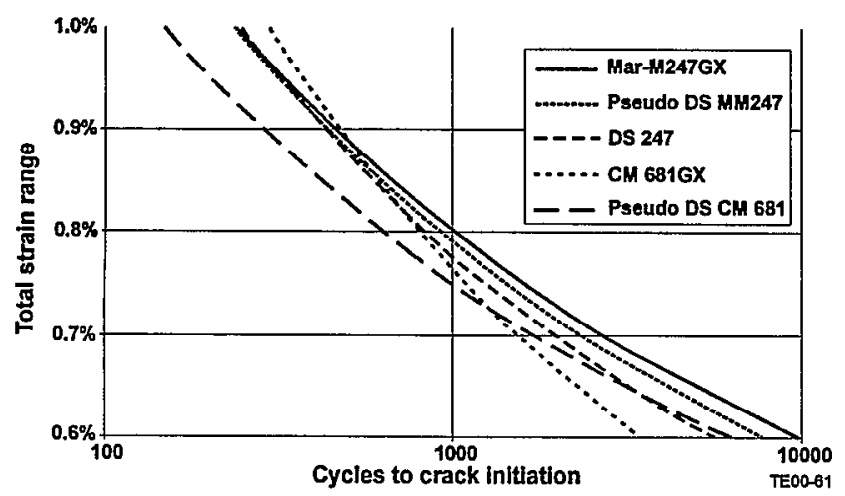

Figure 17. Hub LCF results from DS/GX and Pseudo DS/GX wheels.

Accordingly, both Mar-M247 and CM 681 alloys and GX and Pseudo DS/GX processing were included in the final scale-up plan.

Nine wheels were cast from Mar-M247 using the Pseudo DS/GX method. There were 16 wheels cast from CM 681, 8 each with the GX and Pseudo DS/GX casting processes. These castings were inspected per the Rolls-Royce Corporation production specification and therefore received a more detailed inspection than any other castings produced in this program to date.

\section{Manufacturing/Affordability Study}

The trade study was intended to assess the potential life cycle cost impacts of alternative designs, materials, and structures in the first-stage turbine wheel of the Model 250 Series IV engine. The inputs to this trade study were wheel casting costs, wheel life, and wheel airfoil temperature capability. Six variants were compared to the production Mar-M246 wheel. The wheel casting cost estimates were prepared by Howmet. The wheel life estimates were based on go-and-blow engine testing and mechanical testing (LCF and FCG). The airfoil temperature capability estimates were based on stress rupture testing of airfoil miniflats.

The first-stage turbine wheels developed under this program offer the two advantages of increased turbine wheel life and increased airfoil temperature capabilities compared to the Mar-M246 production configuration wheel. The increased turbine wheel life translates directly into increased time between overhaul for the engine hot section, with a subsequent reduction in the direct operating cost (DOC) of the engine. The increased airfoil temperature capabilities result in increased shaft horsepower output of the engine, which in turn leads to a potential increase in customer value. The potential for both the decreased DOC and increased net customer value for each alloy/structure combination, relative to the current production baseline first-stage turbine wheel, was assessed separately. Details of the trade study are shown in Table II.

The impact on engine DOC is a tradeoff between the increased turbine wheel life and cost. The Mar-M247 GX thick rim wheel shows a substantial improvement in engine DOC compared to the current production baseline configuration $(-2.2 \%)$. The $\mathrm{CM} 681$ GX provides an incremental improvement over the Mar-M247 GX wheel $(-2.5 \%$ versus $-2.2 \%)$. The Pseudo DS/GX and DS/GX processing showed an adverse effect on engine DOC, since these techniques increase wheel manufacturing cost and do not provide additional wheel life.

As with the DOC analysis, there is a tradeoff between the increased temperature capability of the turbine wheel and the increased cost of advanced wheel castings. For the alloy/structure combinations studied, however, the increase in customer value due to the increased temperature capability far outweighs the increase in casting cost. Thus, the wheels with the greatest increase in temperature capability also have the greatest potential for increased net customer value.

In summary, this trade study suggests that both the advanced alloy and the advanced processing, either alone or in combination, offer significant cost benefits over the current production practice.

\section{Frequency/High Cycle Fatigue Blade Testing}

Blade vibratory modes and blade high cycle fatigue (HCF) strength were determined from finish machined Mar-M247 Pseudo DS/GX and CM 681 Pseudo DS/GX wheels. The test is required to determine which blade vibratory modes lie within the engine operating range, to verify the consistency of fabrication, and to compare the fatigue strength to past Model 250 first-stage wheel experience. Blade frequencies were determined through bench frequency testing. Blade fatigue strength was determined at ambient temperature by securing an individual blade to a fixed base and exciting the airfoil with an acoustical siren that varies in excitation energy and frequency. The crystallographic orientation texture associated with the Pseudo DS/GX processing produces a 10 to $15 \%$ reduction in the effective elastic modulus of the airfoil in first bend mode, with a resultant 5 to $10 \%$ reduction in blade frequency in first bend. However, no detrimental engine order coincidences that would interfere with normal engine operation were observed. The Pseudo DS/GX processing reduced HCF blade strength 30 to $40 \%$. Additional analysis would be required to assess this lower capability.

Table II. AMSTE manufacturing/affordability study.

\begin{tabular}{|c|c|c|c|c|c|c|c|c|c|}
\hline \multirow{2}{*}{$\frac{\text { Alloy }}{\text { Mar-M246 }}$} & \multirow{2}{*}{$\begin{array}{l}\begin{array}{l}\text { Wheel } \\
\text { structure }\end{array} \\
\text { Equiaxed }\end{array}$} & \multirow{2}{*}{ Design } & \multirow{2}{*}{$\begin{array}{l}\text { Casting } \\
\text { acquisition } \\
\text { cost }\end{array}$} & \multirow{2}{*}{$\begin{array}{l}\text { Change in } \\
\text { turbine } \\
\text { wheel } \\
\text { list price } \\
\text { Baseline }\end{array}$} & \multirow{2}{*}{ Life } & \multirow{2}{*}{$\begin{array}{l}\begin{array}{l}\text { Increased } \\
\text { airfoll } \\
\text { temperature }\end{array} \\
\text { Baseline }\end{array}$} & \multicolumn{2}{|c|}{$\begin{array}{l}\text { Increased } \\
\text { output shaft Change } \\
\text { horsepower in DOC }\end{array}$} & \multirow{2}{*}{$\begin{array}{l}\text { Net } \\
\text { increase in } \\
\text { customer } \\
\text { value } \\
\text { Baseline }\end{array}$} \\
\hline & & & & & & & Baseline & Baseline & \\
\hline \multirow[t]{3}{*}{ Mar-M247 } & $\mathrm{GX}$ & Thick rim & $1.6 x$ & $26 \%$ & $2 x$ & $+0^{\circ} \mathrm{C}$ & 0 & $-2.2 \%$ & 0 \\
\hline & Pseudo DS/GX & Thick rim & $2.7 X$ & $71 \%$ & $2 x$ & $+14^{\circ} \mathrm{C}$ & $4.3 \%$ & $-0.8 \%$ & $8 \%$ \\
\hline & $D S / G X$ & Thick rim & $8.0 \mathrm{X}$ & $300 \%$ & $2 x$ & $+24^{\circ} \mathrm{C}$ & $7.3 \%$ & $+5.9 \%$ & $12 \%$ \\
\hline \multirow[t]{3}{*}{ CM 681} & $G X$ & Thick rim & $2.7 X$ & $71 \%$ & $3 x$ & $+4^{\circ} \mathrm{C}$ & $1.3 \%$ & $-2.5 \%$ & $2 \%$ \\
\hline & Pseudo DS/GX & Thick rim & $4.0 \mathrm{X}$ & $129 \%$ & $3 x$ & $+21^{\circ} \mathrm{C}$ & $6.2 \%$ & $-1.4 \%$ & $11 \%$ \\
\hline & DS/GX & Thick rim & $9.3 x$ & $357 \%$ & $3 x$ & $+31^{\circ} \mathrm{C}$ & $9.2 \%$ & $+3.1 \%$ & $15 \%$ \\
\hline
\end{tabular}




\section{Spin Pit Burst Testing of Wheels}

Burst speed of finish machined Mar-M247 Pseudo DS/GX, CM 681 Pseudo DS/GX, and CM 681 GX wheels were determined in spin pit testing at ambient temperature. This test is conducted in a spin pit capable of rotational speeds up to $85,000 \mathrm{rpm}$. Burst testing validates design calculations of both wheel burst speed and failure origin. All three wheels burst in a radial mode, which is considered normal, at speeds commensurate with the ultimate tensile strength of the materials as determined by specimen testing.

\section{Cyclic Engine Testing}

Historically, the most accurate means of evaluating crack initiation and growth in the Model 250 engine turbine wheels has been through cyclic engine testing known as go-and-blow testing. Only in engine operation are the actual rim-to-web thermal gradients achieved during various conditions such as start, acceleration, deceleration, and shutdown. The extensive experience of Rolls-Royce Corporation and the data base with this accelerated test allow for efficient screening of new designs, materials, and processes.

This test is more severe on the turbine wheel than an actual engine operating cycle (start-run-stop), producing LCF crack growth rates of approximately twice those experienced in actual service. The most important parameter in determining the life of the Model 250 turbine wheels is the length of the wheel rim cracks known as " $\mathrm{B}$ " cracks. A "B" crack is a crack that is initiated on the outer diameter of the wheel rim (the platform between the blades) and extends down the machined surface of the rim leading or trailing edges. Engine operational instructions define a maximum allowable " $\mathrm{B}$ " crack length for continued operation in service.

A CM $681 \mathrm{GX}$ first-stage turbine wheel was fabricated and assembled into a Model $250-\mathrm{C} 47 \mathrm{~B}$ engine. The test engine completed 2000 cycles of go-and-blow testing in 1000 cycle intervals. At the end of each 1000 cycle interval, the wheel was removed from the engine and inspected for cracks by FPI. The lengths of the cracks were measured and recorded during each inspection.

The results of the advanced alloy wheel go-and-blow engine test are compared to go-and-blow tests for a current production firststage turbine wheel and the baseline Mar-M247 GX configuration in Figure 18. It is evident the baseline Mar-M247 GX

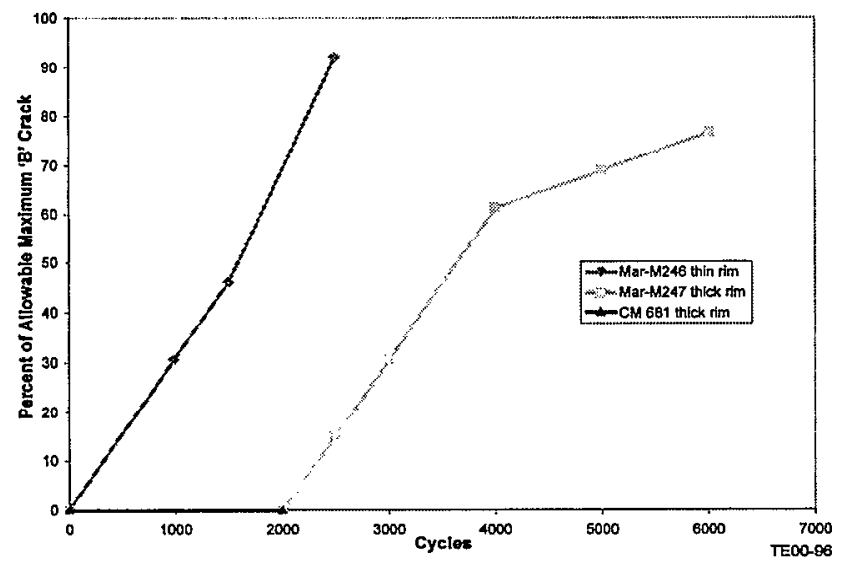

Figure 18. Maximum "B" crack length versus go-and-blow engine cycles. configuration offers a significant improvement $(>2 X)$ over the current production first-stage wheel. The advanced alloy wheel results were also promising. Additional engine testing of this wheel would be required to confirm the improved crack growth resistance of this alloy.

\section{Acknowledgements}

The authors thank Robert Miner, formerly at NASA Glenn, and Brian Griffin and Bruce Allmandinger at Howmet LaPorte Casting Corporation for their technical contributions to this program. This program was supported in part by the NASA Glenn Research Center under Cooperative Agreement NCC3-387.

\section{References}

1) K. Harris, G. L. Erickson, S. L. Sikkenga, W. D. Brentnall, J. M. Aurrecoechea and K. G. Kubarych, "Development of the Rhenium Containing Superalloys CMSX- $4^{\otimes}$ and CM 186 LC $^{\circledR}$ for Single Crystal Blade and Directionally Solidified Vane Applications in Advanced Turbine Engines," Superalloys, 1992 (Warrendale, Pennsylvania, TMS, 1992, pp 297-306).

2) G. L. Erickson, "The Development and Application of CMSX-10 ${ }^{\circledR}$," Superalloys, 1996 (Warrendale, Pennsylvania, TMS, 1996, pp 35-44).

3) Private communication from John Eridon, CannonMuskegon to Rolls-Royce Corporation, 1993.

4) C. T. Sims and W. C. Hagel, The Superalloys, (John Wiley \& Sons, Inc., 1972, pp. 500-503).

5) J. L. Mallardi, "From Teeth to Jet Engines," (presented to Gas Turbine Society of Japan June 5, 1992) Howmet Corporation, 1992, Greenwich, CT.

6) Howmet Technical Bulletin No. 3000, "Grainex ${ }^{\circledR}$ Cast MarM 247 Alloy," 1989, Greenwich, CT.

7) C. T. Sims and W. C. Hagel, The Superalloys, (John Wiley \& Sons, Inc., 1972, pp. 252-256).

8) R. W. Broomfield, et al., "Development and Turbine Engine Performance of Three Advanced Rhenium Containing Superalloys for Single Crystal and Directionally Solidified Blades and Vanes," (Paper presented at the 1997 ASME [IGTI] TURBO EXPO '97 Conference, Orlando, Florida, June 1997).

9) K. Harris, G. L. Erickson, and R. E. Schwer, "Development of a High Creep Strength, High Ductility, Cast Superalloy for Integral Turbine Wheels" (Paper presented at the 1982 AIME Conference, Dallas, Texas, February 1982).

10) B. A. Ewing, "A Solid to Solid HIP-Bond Processing Concept for the Manufacture of Dual-Property Turbine Wheels for Small Gas Turbines," Superalloys, 1980 (Warrendale, Pennsylvania, TMS, 1980, pp 169-178).

11) J.H. Moll, J.H. Schwertz, and V.K. Chandhok, "P/M DualProperty Wheels for Small Engines," Conference Proceedings-Progress in Powder Metallurgy 1981, (Metal Powder Industries Federation, Vol. 37, 1982, pp. 303-319). 